\title{
Interventions Addressing Depression and HIV-Related Outcomes in People with HIV
}

\author{
Noelle A. Mendez ${ }^{1}$ (D) Daniel Mayo $^{1}$ (D) $\cdot$ Steven A. Safren ${ }^{1}$ (C) \\ Accepted: 21 April 2021 / Published online: 20 May 2021 \\ (C) The Author(s), under exclusive licence to Springer Science+Business Media, LLC, part of Springer Nature 2021
}

\begin{abstract}
Purpose of Review People with HIV (PWH) are more likely to experience depression than those without HIV. Depression is not only distressing and interfering in and of itself, but it is also consistently associated with non-adherence to antiretroviral treatment (ART). Accordingly, research and clinical priorities require updated knowledge about interventions that address depression in PWH.

Recent Findings Twenty efficacy trials and nine pilot studies since a 2009 review emerged in the literature review search. Of these, 11 and 6 respectively had a depression-related inclusion criterion. The intervention strategies included individual psychotherapy $(n=6)$, group therapy $(n=6)$, telehealth $(n=3)$, and antidepressant medication $(n=5)$. Generally, these interventions demonstrated acute efficacy for improving depression symptoms in PWH, with some also addressing ART non-adherence. However, not all studies collected follow-up data. Furthermore, trials that addressed depression but did not specifically address nonadherence did not also show adherence improvements.

Summary Existing interventions for depression have demonstrated efficacy in PWH, and these may have both positive mental and physical health outcomes. Future trials should measure and boost longer-term effects. It would be useful to incorporate adherence interventions into depression treatment to improve self-care behaviors and health outcomes.
\end{abstract}

Keywords HIV $\cdot$ Depression $\cdot$ ART adherence $\cdot$ Intervention

\section{Introduction}

People with HIV (PWH) experience a higher prevalence of depression than the general population. In nationally representative and clinic-based samples of PWH [1-4], depression ranges from 12.4 to $67 \%$, which is three to eight times more than the general population $(4.4 \%)$ [5]. Depression can present with a variety of symptoms, such as low mood or energy, lack of interest or

This article is part of the Topical Collection on Behavioral-Bio-Medical Interface

Steven A. Safren

ssafren@miami.edu

Noelle A. Mendez

nmendez2@miami.edu

Daniel Mayo

dmayo@miami.edu

1 Department of Psychology, University of Miami, Coral Gables, FL, USA concentration, and feelings of guilt, as well as changes in appetite, sleep habits, and psychomotor activity [6]. Many of these symptoms make it challenging to engage in self-care activities and effectively manage the strict regimen of HIV care.

Consequently, depression is associated with poor HIV health outcomes. PWH with depression are more likely to be nonadherent to antiretroviral therapy (ART) medication than PWH without depression [7, 8]. Because depression can cause fatigue and low energy, taking ART and attending medical appointments can be difficult. An inconsistent sleep schedule or lack of appetite, if ART must be taken with food to avoid gastrointestinal symptoms, may also make it challenging to take ART daily. There is some evidence that depression can be associated with poor HIV progression through lower CD4 cell counts, higher viral loads, and higher AIDS diagnosis rate [9, 10].

In 2009, Sherr et al. [11] conducted a systematic review of 90 published studies on depression interventions for PWH. The review found that psychological interventions, particularly those with a cognitive-behavioral component, had the highest efficacy. Psychotropic and HIV-specific health psychology interventions were also generally efficacious. 
Physical therapies and psychosocial interventions, however, were less efficacious, if at all. Since Sherr et al.'s [11] review, interventions for PWH with depression have continued to evolve to maximize their efficacy.

Our review covers studies published after 2009 since the published review undertaken by Sherr et al. [11]. We included both treatment studies that only enrolled participants with clinical depression and intervention studies that did not require a depression criterion to enroll. We also included psychological, educational, and medication-based intervention studies. This review only uses one publication per intervention study, as some had several publications - specifically, the publication with the most comprehensive depression outcomes. Our review also covers adherence and HIV health outcomes, if reported by the study.

\section{Method}

In November 2020, we searched for recent publications of intervention studies in Google Scholar, PubMed, and PsycINFO. Key terms in the search included HIV, depression, intervention, and treatment. We restricted the publication time from 2009 to the present and excluded publications from 2009 if included in Sherr et al.'s [11] review. Studies were limited to adults, age 18 and older. A total of 20 studies were chosen for review, and nine pilot studies were summarized in the Discussion section. We grouped interventions into four categories: individual psychosocial, group therapy, telehealth, and antidepressants. Table 1 displays the studies included in this review.

\section{Individual Psychosocial Interventions}

Since Sherr et al.'s [11] review, six studies of individual psychosocial interventions have emerged in the literature. All six studies consisted of randomized controlled trials that examined depression as either a primary or secondary outcome. Of these studies, four focused on cognitive-behavioral therapy (CBT) and adherence counseling, and the remaining two studies focused on a variation of self-care strategies. Furthermore, only four of the six studies included a depression criterion.

The first efficacy study from our research program is based on our initial pilot work [12]. We assessed cognitivebehavioral therapy for adherence and depression (CBT-AD) for PWH, depression, and opioid dependence [13]. To participate, individuals must have had a diagnosis of current or subsyndromal depression. Eighty-nine patients in active substance use treatment were randomized into two conditions, with both receiving one medication adherence counseling session (Life-Steps) [14]. Following the Life-Steps session, participants in the intervention condition received eight 50-min sessions that integrated this form of medication adherence counseling with traditional CBT techniques for depression. The control did not receive any further intervention. Three months after initiating treatment, patients who received CBT-AD improved more in ART adherence and decreased more in depression symptoms than the control. At 6- and 12 -month visits after baseline, depressive symptoms remained lower, and CD4 cell count showed an improvement for the intervention group, but adherence gains were not sustained. Although the intervention provided sustained improvements in depressive symptoms, continued adherence counseling may contribute to long-term ART adherence for PWH with depression and opioid dependence.

To further test the efficacy of CBT-AD, our group [15•] conducted a randomized three-arm trial among $240 \mathrm{PWH}$ prescribed ART. The depression inclusion criterion consisted of a current diagnosis or residual symptoms for patients prescribed antidepressants. Each condition received one session of LifeSteps adherence counseling. One arm involved 11 sessions (1h) of CBT-AD sessions, focused on depression treatment through a CBT model, which also incorporated Life-Steps adherence counseling. The second arm received time and attention-matched sessions of a different treatment for depression, information, and supportive psychotherapy with adherence counseling (ISP-AD). The control arm received no further intervention after the single Life-Steps session. Compared to Life-Steps only, depression symptoms and ART adherence significantly improved in the CBT-AD and ISP-AD conditions 4 months after treatment. These improvements were generally sustained over 8- and 12-month follow-up assessments, with no significant difference between the CBT-AD and ISP-AD conditions. In other words, adherence counseling alone was not enough to improve adherence in a depressed population. Upon addressing depressive symptoms with either psychotherapy, participants appeared to benefit from adherence counseling regardless of the specific type of psychotherapy intervention.

Another intervention addressed body image disturbance and psychological symptoms, similar to CBT-AD, while also incorporating adherence counseling. Blashill et al. [16] recruited 44 sexual minority men with HIV who reported concerns about their appearance. The inclusion criteria did not require a depression diagnosis in addition to the distressing body concerns. All participants received one session of LifeSteps adherence counseling and a WisePill device to track real-time medication dosing. Half the participants received five biweekly meetings to review ART adherence. The other half received 12 weekly sessions (50-min) of CBT for body image and self-care (CBT-BISC), which included time to review ART adherence. Compared to the control, participants in CBT-BISC showed a reduction in body image disturbance at 3- and 6-month assessments and depressive symptoms at the 6-month assessment only. The intervention saw ART adherence improved at the 3-month assessment, but results varied at 
Table 1 Details of all studies included in this review

\begin{tabular}{|c|c|c|c|c|c|}
\hline Authors (year) & Population $(N)$ & Depression criteria & Intervention & Comparison condition(s) & Findings \\
\hline \multicolumn{6}{|l|}{ Individual } \\
\hline Safren et al. (2012) & $\begin{array}{l}\text { Adults in the USA } \\
\text { currently enrolled in } \\
\text { opioid treatment for at } \\
\text { least a month }(N=89)\end{array}$ & $\begin{array}{l}\text { Have a diagnosis } \\
\text { of current or } \\
\text { subsyndromal } \\
\text { depressive } \\
\text { mood disorder }\end{array}$ & $\begin{array}{l}\text { Cognitive-behavioral } \\
\text { therapy for adherence } \\
\text { and depression } \\
\text { (CBT-AD) }\end{array}$ & $\begin{array}{l}\text { Enhanced treatment as } \\
\text { usual (ETAU), which } \\
\text { is one Life-Steps } \\
\text { session }\end{array}$ & $\begin{array}{l}\text { Compared to ETAU, } \\
\text { depression and } \\
\text { adherence were } \\
\text { improved at } \\
\text { post-treatment (3 } \\
\text { months) for CBT-AD. } \\
\text { At the 6- and 12-month } \\
\text { assessments after } \\
\text { baseline, depression and } \\
\text { CD4 cell count } \\
\text { improved for CBT-AD. }\end{array}$ \\
\hline Safren et al. (2016) & $\begin{array}{l}\text { Adults in the US New } \\
\text { England region who } \\
\text { have had no CBT or } \\
\text { adherence } \\
\text { intervention in the } \\
\text { past year }(N=240)\end{array}$ & $\begin{array}{l}\text { Have a diagnosis } \\
\text { of depression or } \\
\text { antidepressant } \\
\text { prescription } \\
\text { with residual } \\
\text { symptoms }\end{array}$ & $\begin{array}{l}\text { Cognitive-behavioral } \\
\text { therapy for adherence } \\
\text { and depression } \\
\text { (CBT-AD) }\end{array}$ & $\begin{array}{l}\text { 1) Information and } \\
\text { Supportive } \\
\text { Psychotherapy with } \\
\text { adherence counseling } \\
\text { (ISP-AD) } \\
\text { 2) Enhanced treatment as } \\
\text { usual, which is one } \\
\text { Life-Steps session }\end{array}$ & $\begin{array}{l}\text { Depression was lowered, } \\
\text { and adherence was } \\
\text { improved at } \\
\text { post-intervention (4 } \\
\text { months), 8-, and } \\
\text { 12-month follow-ups } \\
\text { for both CBT-AD and } \\
\text { ISP-AD conditions, } \\
\text { compared to ETAU. No } \\
\text { differences between } \\
\text { CBT-AD and ISP-AD } \\
\text { at any timepoint. }\end{array}$ \\
\hline $\begin{array}{l}\text { Blashill et al. } \\
\text { (2017) }\end{array}$ & $\begin{array}{l}\text { Sexual minority men in } \\
\text { the US who reported } \\
\text { elevated concerns } \\
\text { about appearance } \\
(N=44)\end{array}$ & $\begin{array}{l}\text { None; required a } \\
\text { score } \geq 16 \text { on } \\
\text { the Body } \\
\text { Dysmorphic } \\
\text { Disorder } \\
\text { modification of } \\
\text { the YBOCS }\end{array}$ & $\begin{array}{l}\text { Life-Steps plus } \\
\text { Cognitive-behavioral } \\
\text { therapy for body image } \\
\text { and self-care } \\
\text { (CBT-BISC) }\end{array}$ & $\begin{array}{l}\text { Life-Steps session plus } \\
\text { biweekly meetings to } \\
\text { review WisePill } \\
\text { adherence }\end{array}$ & $\begin{array}{l}\text { CBT-BISC reduced body } \\
\text { image disturbance at the } \\
\text { 3- and 6-month visits, } \\
\text { and depression at the } \\
\text { 6-month visit only. } \\
\text { High adherence from } \\
\text { baseline cannot detect } \\
\text { effects, although } \\
\text { CBT-BISC generally } \\
\text { increased adherence and } \\
\text { ETAU reduced a little. }\end{array}$ \\
\hline $\begin{array}{l}\text { Simoni et al. } \\
\text { (2013) }\end{array}$ & $\begin{array}{l}\text { Adults of Mexican } \\
\text { descent, Spanish } \\
\text { speaking, in El Paso, } \\
\text { TX currently in HIV } \\
\text { care }(N=40)\end{array}$ & BDI-IA $\geq 10$ & $\begin{array}{l}\text { Life-Steps plus culturally } \\
\text { informed } \\
\text { cognitive-behavioral } \\
\text { therapy for adherence } \\
\text { and depression } \\
\text { (CBT-AD) delivered in } \\
\text { Spanish }\end{array}$ & Treatment as usual & $\begin{array}{l}\text { The CBT-AD condition } \\
\text { saw a greater decrease } \\
\text { in depression scores and } \\
\text { improvement in ART } \\
\text { adherence than the } \\
\text { control at the 6- and } \\
\text { 9-month timepoints } \\
\text { after starting the } \\
\text { intervention. }\end{array}$ \\
\hline $\begin{array}{l}\text { Ironson et al. } \\
\text { (2012) }\end{array}$ & $\begin{array}{l}\text { Adults in the South } \\
\text { Florida region of the } \\
\text { USA with a CD4 cell } \\
\text { count between } 100 \\
\text { and } 600(N=244)\end{array}$ & None & $\begin{array}{l}\text { Trauma-writing exercise } \\
\text { for } 4 \text { days }\end{array}$ & $\begin{array}{l}\text { Daily-event-writing for } 4 \\
\text { days }\end{array}$ & $\begin{array}{l}\text { At 1-, 6-, and 12-month } \\
\text { assessments, women in } \\
\text { the trauma-writing } \\
\text { exercise reported lower } \\
\text { depression and } \\
\text { HIV-related symptoms } \\
\text { than men. For the same } \\
\text { timepoints, men in the } \\
\text { daily-event-writing } \\
\text { exercise reported lower } \\
\text { depression compared to } \\
\text { men in the } \\
\text { trauma-writing exercise. }\end{array}$ \\
\hline Eller et al. (2013) & $\begin{array}{l}\text { Adults in South Africa, } \\
\text { Puerto Rico, and } 10\end{array}$ & $\begin{array}{l}\text { "Yes" to the } \\
\text { Depressive } \\
\text { Symptom }\end{array}$ & $\begin{array}{l}\text { HIV/AIDS Symptom } \\
\text { Management Manual }\end{array}$ & $\begin{array}{l}\text { Nutritional manual plus } \\
\text { a } 30 \text {-min explanation } \\
\text { of it }\end{array}$ & $\begin{array}{l}\text { The intervention group } \\
\text { saw a decrease in } \\
\text { depressive symptoms at }\end{array}$ \\
\hline
\end{tabular}


Table 1 (continued)

Comparison condition(s) Findings

\begin{tabular}{|c|c|c|c|}
\hline Authors (year) & Population $(N)$ & Depression criteria & Intervention \\
\hline & $\begin{array}{l}\text { US sites currently in } \\
\text { HIV care }(N=222)\end{array}$ & $\begin{array}{l}\text { Self-Report } \\
\text { item }\end{array}$ & $\begin{array}{l}\text { plus a } 30-\mathrm{min} \\
\text { explanation of it }\end{array}$ \\
\hline \multicolumn{4}{|l|}{ Group } \\
\hline $\begin{array}{l}\text { Heckman et al. } \\
\text { (2011) }\end{array}$ & $\begin{array}{l}\text { Older adults (age } 50+) \text { in } \\
\text { the USA }(N=295)\end{array}$ & $\mathrm{BDI} \geq 10$ & $\begin{array}{l}\text { Coping improvement } \\
\text { group }\end{array}$ \\
\hline $\begin{array}{l}\text { Gonzalez-Garcia } \\
\text { et al. (2014) }\end{array}$ & $\begin{array}{l}\text { Adults in Spain with } \\
\text { diagnosed HIV for at } \\
\text { least } 15 \text { years }(N=40)\end{array}$ & None & $\begin{array}{l}\text { Mindfulness-based } \\
\text { cognitive therapy } \\
\text { (MBCT) }\end{array}$ \\
\hline $\begin{array}{l}\text { Gayner et al. } \\
\text { (2012) }\end{array}$ & $\begin{array}{l}\text { Gay men with HIV in } \\
\text { Canada }(N=117)\end{array}$ & $\begin{array}{l}\text { None, but } \\
\text { excluded if they } \\
\text { have active } \\
\text { current major } \\
\text { depression }\end{array}$ & $\begin{array}{l}\text { Mindfulness-based stress } \\
\text { reduction (MBSR) } \\
\text { group }\end{array}$ \\
\hline
\end{tabular}

depression
Hecht et al. (2018) Adults in the USA who None were not on or are unlikely to start ART $(N=177)$
Mindfulness-based stress reduction (MBSR) group
Continued routine HIV care visits

Followed their standard care

HIV education group

Waitlist for the intervention schema-focused for reducing depression

MINI diagnosis of Culturally sensitive group support psychotherapy

Health education group
) Interpersonal support group

2) Access to community mental health centers upon request

Nakimuli-Mpungu Adult patients at an urban HIV care center in Uganda $(N=150)$ depression

BDI $>14$$$
\text { (1) }
$$

the 1-month follow-up but increased to baseline levels at the 2-month follow-up.

Both interventions had reduction in depression symptoms compared to control after completing the intervention and at 4- and 8-month follow-ups. Intervention groups showed no difference in depression symptoms.

At the 5-month follow-up, the intervention showed greater improvements in CD4 cell count and depressive symptoms than the control.

Both groups reported improved depression at the 2- and 6-month visits after baseline. For the MSBR group, mindfulness ability increased at both timepoints which correlated with decreased depression.

Depression improved from baseline to 3-month assessment in the MBSR group, with trends at the 12-month assessment too. No difference in the rate of ART initiation and CD4 cell count between the two groups.

The intervention reduced depression symptoms directly after treatment.

No differences between groups immediately after the intervention. At the 6-month post-treatment assessment, the treatment group had lower depression scores than those in the control group.

Telehealth

Heckman et al.

GDS $\geq 10$

Telephone-administered

1) supportive-expressive depression compared to
Tele-SEGT reduced 
Table 1 (continued)

\begin{tabular}{|c|c|c|c|c|}
\hline Authors (year) & Population $(N)$ & Depression criteria & Intervention & Comparison condition \\
\hline & $\begin{array}{l}\text { Older adults (age } 50+) \\
\text { from } 24 \text { states in the } \\
\text { USA }(N=361)\end{array}$ & & $\begin{array}{l}\text { group therapy } \\
\text { (tele-SEGT) }\end{array}$ & $\begin{array}{l}\text { Telephone-administe } \\
\text { red coping } \\
\text { effectiveness training } \\
\text { (tele-CET) group } \\
\text { 2) Standard care (SC) }\end{array}$ \\
\hline $\begin{array}{l}\text { Heckman et al. } \\
\text { (2017) }\end{array}$ & $\begin{array}{l}\text { Adults in rural } \\
\text { communities from } 28 \\
\text { states in the USA } \\
(N=132)\end{array}$ & $\begin{array}{l}\text { Met DSM-IV } \\
\text { criteria for } \\
\text { MDD, MDD in } \\
\text { partial } \\
\text { remission, or } \\
\text { dysthymic } \\
\text { disorder using } \\
\text { the } \\
\text { PRIME-MD }\end{array}$ & $\begin{array}{l}\text { Telephone-delivered } \\
\text { interpersonal } \\
\text { psychotherapy } \\
\text { (tele-IPT) }\end{array}$ & None \\
\hline $\begin{array}{l}\text { Himelhoch et al. } \\
\text { (2013) }\end{array}$ & $\begin{array}{l}\text { Low-income, } \\
\text { urban-dwelling adults } \\
\text { in the USA }(N=34)\end{array}$ & $\begin{array}{l}\text { PHQ-9 } \geq 12 \text { and } \\
\text { did not endorse } \\
\text { suicidality }\end{array}$ & $\begin{array}{l}\text { Telephone-CBT (T-CBT) } \\
\text { for depression }\end{array}$ & $\begin{array}{l}\text { Face-to-face standard } \\
\text { care CBT therapy in } \\
\text { their HIV clinic }\end{array}$ \\
\hline
\end{tabular}

Antidepressants

Pence et al. (2015)
Adults taking or beginning ART $(N=304)$
Pyne et al. (2011) US Veterans with depressive symptoms in VA care $(N=249)$

Tsai et al. (2013) Marginally housed or homeless adults in the USA; if CD4 $<350$ need to be taking ART, no psychiatric care within past 6 months $(N=137)$

Tsai et al. (2010)

\footnotetext{
Homeless and marginally housed
}

PHQ-9 $\geq 10$
Measurement-based care provided by depression care managers. Patients were prescribed antidepressants if clinically indicated.

PHQ-9 $\geq 10$

$$
\begin{aligned}
& \text { care model (HITIDES) } \\
& \text { with a depression care } \\
& \text { team }
\end{aligned}
$$

Stepped care/collaborative Treatment as usual

\section{ETAU (doctors have been informed of depression care model)}

At the 6-but not 12-month follow-up, the intervention group had lower depression severity and higher chance of depression remission. No differences in ART adherence or HIV outcomes.

Depression symptom reduction and remission at 6- but not 12-month follow-up, compared to treatment as usual. At the 12-month follow-up, the stepped-care condition reported more depression-free days.

Depressive symptoms improved more for the intervention condition than the control, across each month of a 9 -month period. No significant differences between groups in ART adherence.

community for psychiatric care

Observational prospective cohort study (REACH study) with assessments

Participants who did not receive antidepressant
After beginning antidepressants, participants had 2.03 
Table 1 (continued)

\begin{tabular}{|c|c|c|c|c|c|}
\hline Authors (year) & Population $(N)$ & Depression criteria & Intervention & Comparison condition(s) & Findings \\
\hline & $\begin{array}{l}\text { adults in the USA, } \\
\text { CD4 <350 }(N=158)\end{array}$ & & $\begin{array}{l}\text { every three months for } \\
\text { several years. } \\
\text { Participants either } \\
\text { eventually received } \\
\text { antidepressant } \\
\text { medication through } \\
\text { their provider or not (no } \\
\text { randomization). }\end{array}$ & $\begin{array}{l}\text { medications (no } \\
\text { randomization) }\end{array}$ & $\begin{array}{l}\text { greater odds of } \\
\text { achieving viral } \\
\text { suppression than those } \\
\text { who never took } \\
\text { antidepressants. } \\
\text { Antidepressant } \\
\text { treatment had larger } \\
\text { effects for those with } \\
\text { moderate to severely } \\
\text { depressed mood at } \\
\text { baseline, not for } \\
\text { minimal and mild } \\
\text { depression. Did not } \\
\text { report on depression } \\
\text { outcomes. }\end{array}$ \\
\hline $\begin{array}{l}\text { Coleman et al. } \\
\text { (2012) }\end{array}$ & $\begin{array}{l}\text { Patients referred for } \\
\text { psychiatric } \\
\text { consultation within } \\
\text { HIV clinic in the USA } \\
(N=124)\end{array}$ & $\begin{array}{l}\text { Have a clinical } \\
\text { referral for } \\
\text { depression from } \\
\text { a psychiatrist }\end{array}$ & $\begin{array}{l}\text { Retrospective chart } \\
\text { review; all patients } \\
\text { received collaborative, } \\
\text { measurement-based } \\
\text { depression care }\end{array}$ & None & $\begin{array}{l}\text { Reduced depression } \\
\text { severity for participants } \\
\text { prescribed } \\
\text { antidepressants at the } \\
\text { referral and those who } \\
\text { initiated after study } \\
\text { enrollment. For the } \\
\text { whole sample, CD4 cell } \\
\text { count increased and } \\
\text { viral load decreased at } \\
\text { the post-treatment } \\
\text { timepoint. }\end{array}$ \\
\hline
\end{tabular}

BDI Beck Depression Inventory, PHQ-9 Patient Health Questionnaire-9 item, YBOCS Yale-Brown Obsessive-Compulsive Scale, GDS Geriatric Depression Scale, MINI Mini-International Neuropsychiatric Interview, DSM-IV Diagnostic and Statistical Manual of Psychological Disorders 4th Edition, PRIME-MD Primary Care Evaluation of Mental Disorders

the 6-month assessment. Because most participants were virally suppressed at baseline, there was likely not enough room to see an effect. Thus, future studies may address this limitation by enrolling only people with a detectable viral load to see viral load outcomes.

An adaptation of CBT-AD was assessed by Simoni et al. [17], who conducted a preliminary randomized controlled trial with 40 PWH of Mexican descent living along the US-Mexico border. Inclusion required at least mild depressive symptoms. All participants received an electronic pillbox to track realtime medication dosing. The intervention condition consisted of 50-min sessions beginning with an initial cultural exploration module, followed by a session of Life-Steps adherence counseling, and five CBT-AD sessions. The CBT-AD condition was culturally adapted for a Latinx population of Mexican descent and delivered in English or Spanish by bilingual therapists. The control condition continued their usual medical HIV care. The CBT-AD condition had a greater reduction in depression scores and improvement in ART adherence than the control at 6- and 9-month visits following the start of the intervention. Similar to the prior study (Blashill et al., 2017), findings suggest adapting CBT-AD to specific PWH populations addresses barriers unique to these groups.
A study by Ironson et al. [18] examined the efficacy of a written intervention for post-traumatic stress, depression, and HIV-related outcomes among 244 PWH. The inclusion criteria did not cover depression, but the study excluded individuals prescribed antidepressants a month before enrollment. All participants completed 20- and 10-min writing exercises daily over 4 days. The experimental condition wrote about an experienced traumatic event for the first prompt, followed by processing probes. The control condition first wrote about their previous day, followed by writing about the current day. Analyses for the sample as a whole showed no differences between the conditions. However, the trauma-writing exercise proved useful for women, who reported lower depression and HIV-related symptoms at 1-, 6-, and 12-month assessments. For men, the control condition reported lower depression compared to the trauma-writing condition across the same timepoints. The findings suggest the importance of assessing how the benefits of individual psychosocial interventions may differ by gender.

Adopting a health-based approach, Eller et al. [19] tested the efficacy of self-care strategies (e.g., reading, prayer) in addressing depressive symptoms among PWH. To participate, individuals needed to self-report depressive symptoms in the 
past week. Two hundred and twenty-two participants randomly received either the self-care HIV/AIDS Symptom Management Manual or a nutritional manual and a 30-min explanation of their respective manual. At the 1-month follow-up, participants who received self-care strategies reported fewer depressive symptoms than the control group. However, the depression symptoms increased at the 2-month follow-up. The researchers did not report on changes in ART adherence or other HIV-related outcomes. Findings suggest that participants may have reduced their use of learned self-care strategies over time. Because symptom management can effectively reduce depression, perhaps future interventions could include a symptom management component to be revisited throughout treatment and maintain the changes.

In the six reviewed studies, the individual psychosocial interventions proved to reduce depression in PWH. Researchers observed both short-term (within 6-month follow-up period) $[13,15 \cdot, 16-19]$ and long-term reductions (later than 6-month follow-up) $[13,15 \cdot, 17,18]$ in depressive symptoms following their proposed intervention. In particular, PWH who participated in CBT combined with adherence counseling addressed their depressive symptoms better and improved their ART adherence $[13,15 \cdot, 16,17]$. An intervention using daily writing showed promising decreases in depressive symptoms, although the writing topic affected men and women differently [18]. Another study using an HIV symptom management manual showed improvements in depression symptoms but did not show lasting effects [19]. Although not every study included a depression criterion $[16,18]$, all studies witnessed improvements in depression. Such findings suggest the importance of utilizing CBT and self-care strategies in conjunction with adherence counseling to improve depression and HIVrelated outcomes among PWH.

\section{Group Therapy Interventions}

Group psychological interventions have a long history of building community and social support for $\mathrm{PWH}$, as well as improving HIV care retention and reducing morbidity [20]. Since Sherr et al.'s [11] review in 2009, we identified six papers on group therapy interventions. The studies consisted of randomized controlled trials designed to reduce depression in PWH, of which half required participants to report depression. Each study adopted a different approach (i.e., coping improvement, mindfulness-based, schema-focused, and culturally tailored) toward depression treatment.

Given the psychosocial effects of aging (e.g., depression and loneliness) $[21,22]$ and increased life expectancies due to improved ART [23], Heckman et al. [24] conducted a threearm randomized controlled trial to address depression among 295 PWH aged 50 or older. For inclusion, participants needed to report mild symptoms of depression or greater. One group consisted of 12 sessions (90-min) focused on improving coping skills, such as appraising stressors related to one's HIV status and aging experience, developing emotion-focused coping skills, and using interpersonal support. Another time and attention-matched group entailed members watching HIV-related videos and discussing its relevance to their personal lives. The control group could access referrals to community health centers but received no further intervention. Although the two interventions did not differ, they found greater reductions in depressive symptoms at intervention completion, 4-, and 8-follow-ups than the control. Both coping enhancement and interpersonal support groups proved to help reduce depressive symptoms for older PWH.

Similarly, Gonzalez-Garcia et al. [25] sought to examine the efficacy of a group-based intervention among people with an HIV diagnosis of at least 15 years and have been on ART for at least 5 years. No depression criterion was required to participate. Data from 40 participants in one control and one treatment group following a randomized controlled trial design were used. The control group continued their routine HIV visits. The intervention group consisted of 2.5-h mindfulnessbased cognitive therapy (MBCT) sessions over 8 weeks, which taught participants to address their depressive mood and understand their mental state. At the 5-month timepoint, results revealed greater improvements in CD4 cell count and depressive symptoms for the MBCT group than the control. Given the positive effects of MBCT at the 5-month timepoint, group interventions with a mindfulness-approach designed for PWH may simultaneously improve depression and HIVrelated outcomes.

Another mindfulness-based intervention conducted by Gayner et al. [26] assessed the efficacy of a mindfulnessbased stress reduction (MBSR) program among 117 gay men with HIV. The inclusion criteria did not cover depression, but the study excluded individuals with active current major depression. Participants were randomly assigned to one of two groups. The MBSR intervention consisted of a day-long group retreat, eight 3-h weekly group sessions, and 1-h homework assignments 6 days a week. The control followed their standard care. Regardless of the group, depression improved for the entire sample at the 2- and 6-month visits after baseline. However, further analysis revealed improved mindfulness ability for the MBSR group, which correlated with decreases in depression at both timepoints. Such findings provide further support for the utilization of mindfulness-based group interventions in addressing depression in PWH.

Expanding on mindfulness-based approaches, Hecht et al. [27•] randomly assigned $177 \mathrm{PWH}$ not currently on ART into either an MBSR group or a control group. Inclusion criteria did not require a depression diagnosis. The MBSR group followed a 2.5 -h weekly session structure for 8 weeks which provided mindfulness meditation training to reduce physical and mental symptoms. Controlling for social attention and 
group interaction time, the control consisted of eight 1.5 -h weekly sessions covering education topics regarding HIV management. Among the MBSR group only, depression improved from baseline to 3-month assessment. Moreover, the MBSR displayed trends toward improvements in depression and negative affect at the 12-month assessment. However, the rate of ART initiation and CD4 cell count did not differ between the two groups. Although mindfulness-based group interventions improve depression [25, 26, 27•], further investigation is required to know whether the effects apply to HIVrelated outcomes.

Adopting a distinct approach toward group interventions, Jalali et al. [28] conducted a randomized controlled trial with 42 men with HIV in prison to test a schema-focused approach for reducing depression. Participants must have presented mild depressive symptoms or greater at baseline but could not have had a clinical depression diagnosis before their incarceration and HIV diagnosis. Half of the participants received 11 sessions (90-min) of schema-focused group therapy, a form of CBT that addresses maladaptive thinking patterns formed in childhood. The remainder of the participants comprised a waitlist for receiving the intervention after the study. At the end of the intervention period, depressive symptoms in the treatment group reduced by half, while the control group displayed a slight increase. But, without a follow-up period, the longitudinal effects of the intervention remain unknown. As one of the only schema-focused treatment in this review, the study still provides promising results for the potential benefits that schema-focused interventions may have on the psychological well-being of PWH with depression.

Expanding on group interventions' potential, NakimuliMpungu et al. [29] assessed a culturally tailored intervention in Uganda for treating depression in $150 \mathrm{PWH}$. To participate, inclusion required a major depression diagnosis. The intervention group completed eight 2-3-h weekly sessions of culturally informed group support psychotherapy (GSP). The GSP sessions focused on coping skills, problem-solving, emotional expression, and income-generating skills, since poverty is positively linked to depression [30]. A time- and attentionmatched comparison group only focused on HIV education. Following the intervention period, no differences were observed between the groups. However, at the 6-month study visit, the intervention group reported lower depression and higher functioning scores than the comparison group. Compared to other studies, the findings indicate that adapting current HIV education to fit different populations' cultural understanding may improve depression outcomes.

Our review shows that PWH who experience depression benefit from group therapy as it reduces their depressive symptoms. The six studies reviewed found that PWH who participated in some form of group therapy reported reduced depression compared to those who received individual therapy or no therapy at all $[24-26,27 \cdot, 28,29]$. Regardless of the type (i.e., coping improvement, mindfulness-based, schemafocused, and culturally tailored), PWH benefited from group therapy as they presented fewer depressive symptoms following the intervention period. Despite half the studies not requiring a depression criterion $[24,28,29]$, short-term effects on depression were displayed across all the studies. One study found that depressive symptoms decreased over the 8-month follow-up period [24], and another found trends toward depressive symptoms decreasing at 12-month follow-up [27•]. The other group intervention studies did not measure longterm effects (greater than 6 months post-intervention) [24-26, 29]. These articles display that group therapy's community-building and social support aspects can reduce depressive symptoms, although these effects need to be examined in the long-term to see if they last.

\section{Telehealth Interventions}

Telehealth has become more popular as a modality for therapy services over the last decade [31]. Since Sherr et al.'s [11] review, we identified three telehealth interventions for our current literature review. All three telehealth studies followed a randomized controlled trial design administered via telephone to reduce depression and required that participants screen for depression. One study examined group therapy, another examined cognitive-behavioral therapy, and the last examined interpersonal psychotherapy.

To assess the feasibility of using telephone-administered group intervention to reduce depression, Heckman et al. [32] conducted a three-arm randomized controlled trial with 361 PWH age 50 or older. Inclusion required mild depressive symptoms or greater. One arm consisted of 12 telephone sessions (90-min) of coping effectiveness training (Tele-CET), which used CBT to teach coping strategies. A time- and attention-matched arm consisted of telephone supportiveexpression group therapy (tele-SEGT), which used humanistic psychology to explore aging and HIV difficulties. The control arm only had access to community health referrals. The teleSEGT arm showed fewer depressive symptoms than the teleCET and control arm immediately after the intervention and at the 8-month assessment. The tele-CET showed fewer depression symptoms, but there was no difference from the standard of care arm at any timepoint. The findings suggest that telephone-based group interventions, particularly SEGT, efficaciously reduce depressive symptoms among older PWH.

Based on this [32], Heckman et al. [33•] tested an individual telephone-administered intervention for PWH with depression living in rural settings. The study included participants diagnosed with major depressive disorder (current or in remission) or dysthymic disorder. One hundred and thirty-two participants were randomly assigned to two conditions. Half of the participants received nine 1-h weekly sessions of telephone interpersonal psychotherapy (tele-IPT), focused on 
addressing emotions related to psychological symptoms and enhancing interpersonal skills. The remainder of the participants received no intervention. This study only examined acute changes in depressive symptoms as the follow-up period was ongoing. The tele-IPT group showed improved depressive symptoms at post-intervention compared to the control. Thus, using tele-IPT could be a useful, promising way to reach populations who live in rural areas.

In addition to reaching rural communities, telephone-based therapy may benefit other marginalized communities, as Himelhoch et al. [34] showed in their study of 34 low-income, urban-dwelling PWH. Individuals with a major depression episode were included, provided that they had not initiated or changed antidepressant medication within 6 weeks of consent. The trial randomized participants to 11 sessions (45-min) of either telephone-administered cognitive behavioral therapy ( $\mathrm{T}$ CBT) or face-to-face CBT. Although the intervention and control did not differ in depression outcomes, depression symptoms decreased in both conditions after the treatment. However, only the T-CBT condition improved in ART adherence. Despite the small sample size and lack of long-term assessment, this has promising implications. For instance, T-CBT might affect depression and adherence outcomes because it takes place in the participant's home, which serves as an immediate reminder to take one's medication and may reduce depressive symptoms associated with adherence. This combination could have beneficial implications for the future of telehealth interventions.

Altogether, the three studies display how telehealth may help PWH experiencing depression who might otherwise not have access to mental health services. Accordingly, telehealth interventions reduce depressive symptoms [32, 33•, 34]. The modality of telehealth interventions varied (i.e., CBT, IPT, and SEGT), yet analyses revealed fewer depressive symptoms across all modalities during post-intervention $[32,33 \bullet, 34]$ and long-term assessments (at 8-month follow-up) [32]. However, only one study [32] included a follow-up period, so further investigation is required to assess telehealth interventions' long-term benefits. Compared to not receiving therapy at all [33•] or treatment-as-usual CBT [34], PWH who received telehealth interventions also reported reductions in depression. The implications of these three studies suggest telehealth may be an excellent option for improving depression and ART adherence among PWH who are in rural communities or experience transportation difficulties.

\section{Antidepressant Medication}

We identified five reports of studies on antidepressant medication therapy published after Sherr et al.'s [11] review. Four studies consisted of prospective trials, which examined effects both before and after an intervention. Of these studies, three consisted of randomized controlled trials, and one consisted of an observational study. The last study was a retrospective trial, where outcomes were only examined after the intervention was completed. All of the studies required a depression criterion for inclusion.

To examine the effects of measurement-based care, Pence et al. [35•] used a prospective randomized design with 304 PWH with depression. The depression inclusion criterion consisted of a current diagnosis of major depression. Participants in the intervention received measurement-based care, which consisted of a depression care manager and HIV provider working together to create participants' antidepressant regimens. The control followed usual care with an HIV provider trained in measurement-based care and could prescribe antidepressants. The intervention condition displayed greater reductions in depression severity than the control at the 6- but not 12-month assessments following treatment. No differences in ART adherence or HIV outcomes were observed between the two arms.

Using a stepped-care model, Pyne et al. [36] conducted a randomized controlled trial where 249 veterans with HIV received either a stepped-care model or their usual care. Inclusion required at least moderate severity of depressive symptoms. The stepped-care model included an HIV depression care team (i.e., depression care manager, psychiatrist, and pharmacist) who provided counseling, psychiatric medication, and referrals to specialty mental health care based on participants' needs. Participants in the control condition received care from an HIV or mental health provider who completed an hour of HIV and depression care training. The stepped-care condition reported improved depressive symptoms and greater remission than the control at the 6- but not 12-month follow-up. Although these effects did not apply at the 12-month follow-up, the stepped-care condition reported more days without depression symptoms than before. Like many other studies on depression treatment, long-term effects were hard to maintain [37].

Using a different approach, Bangsberg's group [38] conducted a randomized controlled trial with 137 marginally housed or homeless PWH. To participate, participants needed a diagnosis of major depressive disorder, minor depressive disorder, or dysthymia. Half of the participants received a weekly fluoxetine prescription via directly observed administration for 6 months and followed by 3 months of self-administration. The other half of the participants were encouraged to seek mental health treatment. During the 9 months, results showed a monthly reduction in depressive symptoms in the intervention compared to the control. However, no differences in ART adherence were observed.

Similarly, Tsai et al. [39] analyzed data from a cohort study (REACH) following 158 homeless and marginally housed PWH with symptoms of depression and a CD4 cell count of less than $350 \mathrm{cell} / \mathrm{mm}^{3}$. Individuals with symptoms of depression or greater at the baseline were enrolled. Throughout the study, 119 participants were prescribed antidepressants at some point. Participants 
completed assessments every 3 months for an average of 2.9 years. Using marginal structural models, the results revealed that participants on antidepressant medications experienced a 2.03 greater odds of achieving viral suppression $(<50$ copies $/ \mathrm{mL})$ than those who never took antidepressant medication. Moreover, antidepressant medication treatment had a larger effect on viral suppression for participants with moderate to severe depression at baseline than those with minimal or mild depression.

A retrospective chart review by Coleman et al. included people receiving care at an HIV clinic who were referred for a psychiatric consultation [40]. Participants were referred to a psychiatric consultation after screening for depression by an HIV care provider. A total of $124 \mathrm{PWH}$ received collaborative, measurement-based care from an infectious disease outpatient department. A team comprised of a case manager, psychiatrist, and a consultation-liaison monitored the participants' antidepressant regimens and made appropriate changes when necessary. Participants completed monthly consultations for an average of 1.8 years. The 66 participants with available pre- and post-test depression scores showed depression severity declined between pre- and post-treatment. Further analyses revealed the decline in depression severity applied to both participants already prescribed antidepressants at the referral and those who initiated antidepressants after. For the sample as a whole, CD4 cell count increased, and viral load decreased at the post-treatment timepoint.

In reviewing these five articles, we found that depression treatments for PWH using antidepressant medication treatment efficaciously reduced depression in the short-term, but long-term effects were mixed. Based on the findings, the use of antidepressant medication resulted in improved depressive symptoms in PWH [35•, 36, 38, 40]. While PWH reported reduced depressive symptom severity after participating in antidepressant medication treatment, the treatment effects, in some studies, provided only short-term benefit (at 6-month follow-up) $[35 \cdot, 36]$. In terms of HIV-related outcomes, some medical record review studies have shown that addressing depression with antidepressants can also improve ART adherence, viral load, and CD4 cell count [39, 40]. However, prospective controlled trials do not show these improvements in health outcomes [35•, 38]. Improving depression alone without addressing HIVspecific behaviors does not appear to improve HIVrelated health outcomes. Reducing depression symptoms is the first step in helping PWH to be then receptive to ART adherence counseling. Overall, antidepressant medication therapy interventions may serve as suitable methods for improving depression in the short-term and may help as longer-term therapy, but should be used in conjunction with other strategies for long-term effects on self-care and HIV outcomes among PWH.

\section{Discussion}

By reviewing the most recent literature on depression interventions for PWH, we identified several types of interventions and modalities. Since the last review in 2009 [11], these depression interventions have been via many forms. We identified a total of 20 studies, with six using individual therapy, six using group therapy, three using telehealth, and five using antidepressants. Of these 20 studies, 11 of the 16 psychosocial trials and all 5 of the antidepressant trials required a depression diagnosis or screening for enrollment. Regardless of a depression criterion, all studies reported that the interventions successfully reduced depressive symptoms, with most of them having greatest effects in the short term. However, not all had withstanding long-term effects or included follow-up appointments to assess this. Among the 15 studies that included follow-up assessments, long-term effects were mixed, with few displaying much greater benefits among the intervention groups compared to the control. Many showed a reduction in depressive symptoms immediately after the intervention period, but then a general regression toward baseline levels of depression at later follow-ups. Generally, individual psychotherapy interventions had longer-term sustained improvements on depression, perhaps because of the intensive, individualized approach. Future interventions should focus on developing strategies to maintain treatment gains long-term after active treatment ends.

A review by Beshai et al. [41] found that mindfulnessbased cognitive therapy and interpersonal therapy show promising effects in preventing depression relapse and recurrence. Moreover, regardless of the modality, therapy was less effective in preventing depressive episodes provoked by negative life events. The authors conclude that perhaps interventions with adaptive skills training and navigating interpersonal obstacles might work more effectively. Including these components in treatment for PWH with depression may be effective as HIV is associated with negative life events, such as medical complications or discrimination [42, 43]. In line with this, interventions could have a more flexible delivery approach to tailor treatment to the client's needs and situation, including negative life events that may develop during treatment. Our group ran a pilot study [44] using a flexible CBT-based approach that frequently involved using client's current circumstances as opportunities to practice treatment skills in real time. Using current life events to demonstrate coping skills might increase chances that clients will use their learned skills as negative life events arise post-treatment.

In addition to improving depression outcomes, it is also essential to consider important self-care health behaviors, such 
as adherence to ART and persistence in care. Taking together the existing evidence so far, interventions that just treat depression do not necessarily improve ART adherence. But, interventions that merge both depression treatment with adherence counseling (e.g., CBT-AD) do seem to have effects on adherence $[13,15 \cdot, 16,17]$. It appears necessary to provide patients with skills or other means to reduce barriers to be adherent to their medications. Interventions that address psychological factors alongside adherence counseling appear to improve ART adherence and depressive symptoms. Following this model, depression can be viewed as a barrier to increasing self-care behaviors, such as adherence, instead of a barrier to adherence itself. Considering the existing models of health behavior change such as the InformationMotivation-Behavioral Skills Model [45], Health Belief Model [46], and the Transtheoretical Model of Behavior Change [47], important aspects of behavior change are ones that are often directly impacted by depression, such as selfefficacy and motivation. Most adherence interventions are based on these behavior change models. Because depression can interfere with most aspects of these models, the interventions must be combined with depression treatment. As a result, after patients with HIV are experiencing less depression, they may be more open to the benefits of counseling or other messaging to assist with self-care strategies.

Beyond the studies identified in the current review, several pilot studies have evaluated emerging interventions. We identified nine pilot studies worth noting. Among the pilot studies, five assessed various types of individual psychosocial interventions, including four therapy-based (i.e., transdiagnostic treatment approach [44], nurse-delivered CBT-AD [48•], problem-solving therapy for adherence and depression [49], and behavioral activation treatment for depression [50]) and one self-care approach (i.e., cognitive-behavioral self-help program and computerized structured writing intervention [51]). Another pilot study examined a group therapy intervention (i.e., HIV counselor-delivered IPT [52]). The remaining three studies adopted a telehealth approach to their interventions (i.e., culturally tailored CBT $[53,54]$ and a computerized stress management training [55]). The majority of studies screened for depression as a criterion for enrollment, except a few [44, 51, 54], and only three included control groups in their study design $[44,48 \cdot, 50]$. Across the studies, the intervention group reported reductions in depression symptoms at 2- [51], 3- [48-, 52-54], and 6-month follow-up assessments $[49,53,54]$, as well as ART adherence and viral load improvements at 4- [44], 6- [49, 53], and 8-month follow-up assessments [44]. However, one pilot study found no difference in depression between the control and intervention group at the 1-month follow-up [55]. Additionally, depression [44, 50], CD4 cell count, and ART adherence [50] did not differ from the baseline and 1- [50], 4-, and 8-month follow-up [44] assessments in two of the pilot studies. Overall, these pilot studies' findings display the evolving nature of depression interventions for PWH and show promise as many results demonstrated depression and HIVrelated outcomes improved.

The field is also turning toward remote interventions that may provide more flexibility and reach a wider population. Due to the COVID-19 pandemic, telehealth is becoming more frequently used for medical and psychotherapy appointments [56-58]. This infrastructure's developments can mean more comprehensive access to care for those who live in rural communities or have structural barriers that make accessing care difficult, such as lack of reliable transportation, childcare responsibilities, or inflexible employment schedules. Providing depression intervention services electronically could improve access to care for those who would not otherwise have it. Also, as posed by Himelhoch et al. [34], it is possible that providing intervention while people are at home might enhance the effects of the intervention such that the improvements in depression are taking place directly in the home environment. Remote interventions might also serve as a reminder to engage in necessary self-care behaviors, such as ART adherence, while at home.

While many efficacious interventions exist for treating depression in PWH, another area that needs more investigation is determining which interventions work best for each client. From this review, it is clear that most of these depression interventions generally work. Instead of applying one intervention type to a whole population, perhaps the delivered intervention could be tailored based on the person, considering their needs and circumstances. Group therapy might be particularly indicated for individuals who lack social support. In contrast, individual therapy might be necessary for others to provide focused, individualized treatment for the patient, including for those who may have social or personality differences that would make benefiting from group treatment more difficult. People with specific characteristics or preferences might be responsive to CBT, while the best option for others might be antidepressants. None of the interventions that arose from our search incorporated both antidepressants and psychotherapy, which might be another avenue to explore to maximize benefits.

Considering the strong association between depression and ART non-adherence, addressing the needs of those with depression can help both individual distress and quality of life, but also, to attain "undetectable = untransmittable" [59] status, it can be of both individual and public health significance. Depression can cause symptoms that lead to a reduction in necessary self-care behaviors that maintain proper HIV health. It seems that treating depression alone does not affect self-care behaviors, but potentially the treatment of depression can turn the volume down on depressive symptoms enough for patients with HIV to optimize their potential benefit from skills-based (motivational interviewing, CBT) adherence counseling. Efficacious interventions exist to treat depression in this population, including one 
that integrates CBT with adherence counseling (CBT-AD); therefore, we must continue to find innovative and effective ways to optimize, disseminate, and implement these interventions to benefit the lives of those affected by HIV.

Funding Funding for author time came from grants 9K24DA040489 and 1P30MH116867 awarded to Dr. Steven Safren.

\section{Declarations}

Human and Animal Rights and Informed Consent All reported studies/ experiments with human or animal subjects performed by the authors have been previously published and complied with all applicable ethical standards (including the Helsinki declaration and its amendments, institutional/national research committee standards, and international/national/institutional guidelines).

Conflict of Interest Noelle Mendez, Daniel Mayo, and Steven Safren report getting paid through grants from $\mathrm{NIH}$ that went to their institution (Safren PI), during the conduct of the study. Dr. Safren also receives royalties from Oxford University Press, Guilford Publications, and Springer/Humana Press for books related to cognitive behavioral therapy.

Disclaimer The content is solely the responsibility of the authors and does not necessarily represent the official views of the National Institute of Mental Health, the National Institute for Drug Abuse, or the National Institutes of Health.

\section{References}

Papers of particular interest, published recently, have been highlighted as:

- Of importance

•- Of major importance

1. Bhatia R, Hartman C, Kallen MA, Graham J, Giordano TP. Persons newly diagnosed with HIV infection are at high risk for depression and poor linkage to care: results from the Steps Study. AIDS Behav. 2011;15:1161-70.

2. Bing EG, Burnam MA, Longshore D, Fleishman JA, Sherbourne $\mathrm{CD}$, London AS, et al. Psychiatric disorders and drug use among human immunodeficiency virus-infected adults in the United States. Arch Gen Psychiatry. 2001;58:721-8.

3. Do AN, Rosenberg ES, Sullivan PS, Beer L, Strine TW, Schulden JD, et al. Excess burden of depression among HIV-infected persons receiving medical care in the United States: data from the Medical Monitoring Project and the Behavioral Risk Factor Surveillance System. Zheng JC, editor. PLoS One. 2014;9:e92842.

4. Gokhale RH, Weiser J, Sullivan PS, Luo Q, Shu F, Bradley H. Depression prevalence, antidepressant treatment status, and association with sustained HIV viral suppression among adults living with HIV in care in the United States, 2009-2014. AIDS Behav. 2019;23:3452-9.

5. World Health Organization. Depression and other common mental disorders: global health estimates: World Health Organization. 2017. https://www.who.int/mental_health/management/ depression/prevalence_global_health_estimates/en/. Accessed 7 Feb 2021.
6. American Psychiatric Association. Diagnostic and statistical manual of mental disorders. Fifth ed. Arlington: American Psychiatric Association. 2013.

7. Marks King R, Vidrine DJ, Danysh HE, Fletcher FE, McCurdy S, Arduino RC, et al. Factors associated with nonadherence to antiretroviral therapy in HIV-positive smokers. AIDS Patient Care STDs. 2012;26:479-85.

8. Tucker JS, Burnam MA, Sherbourne CD, Kung F-Y, Gifford AL. Substance use and mental health correlates of nonadherence to antiretroviral medications in a sample of patients with human immunodeficiency virus infection. Am J Med. 2003;114:573-80.

9. Carrico AW, Riley ED, Johnson MO, Charlebois ED, Neilands TB, Remien RH, et al. Psychiatric risk factors for HIV disease progression: the role of inconsistent patterns of antiretroviral therapy utilization. J Acquir Immune Defic Syndr. 2011;56:146-50.

10. Leserman J. Role of depression, stress, and trauma in HIV disease progression. Psychosom Med. 2008;70:539-45.

11. Sherr L, Clucas C, Harding R, Sibley E, Catalan J. HIV and depression - a systematic review of interventions. Psychol Health Med. 2011;16:493-527.

12. Safren SA, O'Cleirigh C, Tan JY, Raminani SR, Reilly LC, Otto MW, et al. A randomized controlled trial of cognitive behavioral therapy for adherence and depression (CBT-AD) in HIV-infected individuals. Health Psychol. 2009;28:1-10.

13. Safren SA, O'Cleirigh CM, Bullis JR, Otto MW, Stein MD, Pollack MH. Cognitive behavioral therapy for adherence and depression (CBT-AD) in HIV-infected injection drug users: a randomized controlled trial. J Consult Clin Psychol. 2012;80:404-15.

14. Safren SA, Otto MW, Worth JL. Life-steps: applying cognitive behavioral therapy to HIV medication adherence. Cogn Behav Pract. 1999;6:332-41.

15. Safren SA, Bedoya CA, O'Cleirigh C, Biello KB, Pinkston MM, Stein MD, et al. Cognitive behavioural therapy for adherence and depression in patients with HIV: a three-arm randomised controlled trial. Lancet HIV. 2016;3:e529-38 This study integrates depression treatment with adherence counseling (CBT-AD) to target both mental and physical health outcomes. This type of approach has important individual and public health implications.

16. Blashill AJ, Safren SA, Wilhelm S, Jampel J, Taylor SW, O'Cleirigh C, et al. Cognitive behavioral therapy for body image and self-care (CBT-BISC) in sexual minority men living with HIV: a randomized controlled trial. Health Psychol. 2017;36:937-46.

17. Simoni JM, Wiebe JS, Sauceda JA, Huh D, Sanchez G, Longoria $\mathrm{V}$, et al. A preliminary RCT of CBT-AD for adherence and depression among HIV-positive Latinos on the U.S.-Mexico border: the Nuevo Día Study. AIDS Behav. 2013;17:2816-29.

18. Ironson $\mathrm{G}$, O'Cleirigh $\mathrm{C}$, Leserman J, Stuetzle R, Fordiani J, Fletcher M, et al. Gender-specific effects of an augmented written emotional disclosure intervention on posttraumatic, depressive, and HIV-disease-related outcomes: a randomized, controlled trial. J Consult Clin Psychol. 2013;81:284-98.

19. Eller LS, Kirksey KM, Nicholas PK, Corless IB, Holzemer WL, Wantland DJ, et al. A randomized controlled trial of an HIV/AIDS Symptom Management Manual for depressive symptoms. AIDS Care. 2013;25:391-9.

20. Bateganya MH, Amanyeiwe U, Roxo U, Dong M. Impact of support groups for people living with HIV on clinical outcomes: a systematic review of the literature. J Acquir Immune Defic Syndr. 2015;68 Suppl 3:S368-74.

21. Gerst-Emerson K, Jayawardhana J. Loneliness as a public health issue: the impact of loneliness on health care utilization among older adults. Am J Public Health. 2015;105:1013-9.

22. Perissinotto CM, Stijacic Cenzer I, Covinsky KE. Loneliness in older persons: a predictor of functional decline and death. Arch 
Intern Med. 2012 [cited 2021 Feb 7];172. Available from: https:// doi.org/10.1001/archinternmed.2012.1993

23. Samji H, Cescon A, Hogg RS, Modur SP, Althoff KN, Buchacz K, et al. Closing the gap: increases in life expectancy among treated HIV-positive individuals in the United States and Canada. Okulicz JF, editor. PLoS One. 2013;8:e81355.

24. Heckman TG, Sikkema KJ, Hansen N, Kochman A, Heh V, Neufeld S. A randomized clinical trial of a coping improvement group intervention for HIV-infected older adults. J Behav Med. Springer. 2011;34:102-11.

25. Gonzalez-Garcia M, Ferrer MJ, Borras X, Muñoz-Moreno JA, Miranda C, Puig J, et al. Effectiveness of mindfulness-based cognitive therapy on the quality of life, emotional status, and CD4 cell count of patients aging with HIV infection. AIDS Behav. 2014;18: 676-85.

26. Gayner B, Esplen MJ, DeRoche P, Wong J, Bishop S, Kavanagh L, et al. A randomized controlled trial of mindfulness-based stress reduction to manage affective symptoms and improve quality of life in gay men living with HIV. J Behav Med. 2012;35:272-85.

27. Hecht FM, Moskowitz JT, Moran P, Epel ES, Bacchetti P, Acree $\mathrm{M}$, et al. A randomized, controlled trial of mindfulness-based stress reduction in HIV infection. Brain Behav Immun. 2018;73:331-9 This group intervention showed short-term improvements in positive affect for those who received mindfulness-based stress reduction, as well as trends in depression improvements at oneyear follow-up.

28. Jalali F, Hasani A, Hashemi SF, Kimiaei SA, Babaei A. Cognitive group therapy based on schema-focused approach for reducing depression in prisoners living with HIV. Int J Offender Ther Comp Criminol. 2019;63:276-88.

29. Nakimuli-Mpungu E, Wamala K, Okello J, Alderman S, Odokonyero R, Mojtabai R, et al. Group support psychotherapy for depression treatment in people with HIV/AIDS in northern Uganda: a single-centre randomised controlled trial. Lancet HIV. 2015;2:e190-9.

30. Galea S, Ahern J, Nandi A, Tracy M, Beard J, Vlahov D. Urban neighborhood poverty and the incidence of depression in a population-based cohort study. Ann Epidemiol. 2007;17:171-9.

31. Vockley M. The rise of telehealth:'Triple Aim,' innovative technology, and popular demand are spearheading new models of health and wellness care. Biomed Instrum Technol. 2015;49:306-20.

32. Heckman TG, Heckman BD, Anderson T, Lovejoy TI, Mohr D, Sutton M, et al. Supportive-expressive and coping group teletherapies for HIV-infected older adults: a randomized clinical trial. AIDS Behav. 2013;17:3034-44.

33. Heckman TG, Heckman BD, Anderson T, Lovejoy TI, Markowitz JC, Shen Y, et al. Tele-interpersonal psychotherapy acutely reduces depressive symptoms in depressed HIV-infected rural persons: a randomized clinical trial. Behav Med. 2017;43:285-95 In light of COVID-19 and the move to remote platforms for many services, evaluating remote interventions is critical. This study found that remote psychotherapy can be distributed efficaciously and to populations that might otherwise not have access to these services.

34. Himelhoch S, Medoff D, Maxfield J, Dihmes S, Dixon L, Robinson $\mathrm{C}$, et al. Telephone based cognitive behavioral therapy targeting major depression among urban dwelling, low income people living with HIV/Aids: Results of a randomized controlled trial. AIDS Behav. 2013;17:2756-64.

35. Pence BW, Gaynes BN, Adams JL, Thielman NM, Heine AD, Mugavero MJ, et al. The effect of antidepressant treatment on HIV and depression outcomes: results from a randomized trial. AIDS. 2015;29:1975-86 In this study, antidepressants were effective in reducing depression symptoms in the short-term. This study also confirms that addressing depression alone is not sufficient for improving ART adherence.
36. Pyne JM, Fortney JC, Curran GM, Tripathi S, Atkinson JH, Kilbourne AM, et al. Effectiveness of collaborative care for depression in human immunodeficiency virus clinics. Arch Intern Med. 2010 [cited $2021 \mathrm{Feb}$ 7];171. Available from: https://doi.org/10. 1001/archinternmed.2010.395

37. Hengartner MP. How effective are antidepressants for depression over the long term? A critical review of relapse prevention trials and the issue of withdrawal confounding. Ther Adv Psychopharmacol. 2020;10:204512532092169.

38. Tsai AC, Karasic DH, Hammer GP, Charlebois ED, Ragland K, Moss AR, et al. Directly observed antidepressant medication treatment and HIV outcomes among homeless and marginally housed HIV-positive adults: a randomized controlled trial. Am J Public Health. 2013;103:308-15.

39. Tsai AC, Weiser SD, Petersen ML, Ragland K, Kushel MB, Bangsberg DR. A marginal structural model to estimate the causal effect of antidepressant medication treatment on viral suppression among homeless and marginally housed persons with HIV. Arch Gen Psychiatry. 2010;67:1282-90.

40. Coleman SM, Blashill AJ, Gandhi RT, Safren SA, Freudenreich O. Impact of integrated and measurement-based depression care: clinical experience in an HIV clinic. Psychosomatics. 2012;53:51-7.

41. Beshai S, Dobson KS, Bockting CL, Quigley L. Relapse and recurrence prevention in depression: current research and future prospects. Clin Psychol Rev. Elsevier. 2011;31:1349-60.

42. Frye V, Nandi V, Egan J, Cerda M, Greene E, Van Tieu H, et al. Sexual orientation- and race-based discrimination and sexual HIV risk behavior among urban MSM. AIDS Behav. 2015;19:257-69.

43. Crothers K, Butt AA, Gibert CL, Rodriguez-Barradas MC, Crystal $\mathrm{S}$, Justice AC. Increased COPD among HIV-positive compared to HIV-negative veterans. Chest. 2006;130:1326-33.

44. Safren SA, Harkness A, Lee JS, Rogers BG, Mendez NA, Magidson JF, et al. Addressing syndemics and self-care individuals with uncontrolled HIV: an open trial of a transdiagnostic treatment. AIDS Behav. 2020;24:3264-78.

45. Fisher JD, Fisher WA, Amico KR, Harman JJ. An informationmotivation-behavioral skills model of adherence to antiretroviral therapy. Health Psychol. 2006;25:462-73.

46. Hochbaum G, Rosenstock I, Kegels S. Health belief model. Washington, DC: United States Public Health Service. 1952.

47. Prochaska JO, DiClemente CC. The transtheoretical approach. In: Norcross JC, Goldfried MR, editors. Handbook of psychotherapy integration. Oxford: 2005;2:147-71.

48. Andersen LS, Magidson JF, O'Cleirigh C, Remmert JE, Kagee A, Leaver M, et al. A pilot study of a nurse-delivered cognitive behavioral therapy intervention (Ziphamandla) for adherence and depression in HIV in South Africa. J Health Psychol. 2018;23:776-87 This study provides a different modality for delivering depression treatment-having psychiatric nurses in an HIV clinic deliver the intervention. This could reduce barriers for those who might otherwise not receive mental health treatment.

49. Abas M, Nyamayaro P, Bere T, Saruchera E, Mothobi N, Simms V, et al. Feasibility and acceptability of a task-shifted intervention to enhance adherence to HIV medication and improve depression in people living with HIV in Zimbabwe, a low income country in SubSaharan Africa. AIDS Behav. 2018;22:86-101.

50. Tull MT, Berghoff CR, Bardeen JR, Schoenleber M, KonkleParker DJ. An initial open trial of a brief behavioral activation treatment for depression and medication adherence in HIVinfected patients. Behav Modif. 2018;42:196-209.

51. Kraaij V, van Emmerik A, Garnefski N, Schroevers MJ, Lo-FoWong D, van Empelen P, et al. Effects of a cognitive behavioral self-help program and a computerized structured writing intervention on depressed mood for HIV-infected people: a pilot randomized controlled trial. Patient Educ Couns. 2010;80:200-4. 
52. Petersen I, Hanass Hancock J, Bhana A, Govender K. A groupbased counselling intervention for depression comorbid with HIV/ AIDS using a task shifting approach in South Africa: a randomized controlled pilot study. J Affect Disord. 2014;158:78-84.

53. Dwight-Johnson M, Aisenberg E, Golinelli D, Hong S, O'Brien M, Ludman E. Telephone-based cognitive-behavioral therapy for Latino patients living in rural areas: a randomized pilot study. Psychiatr Serv. 2011;62:936-42.

54. Junkins A, Psaros C, Ott C, Azuero A, Lambert CC, Cropsey K, et al. Feasibility, acceptability, and preliminary impact of telemedicine-administered cognitive behavioral therapy for adherence and depression among African American women living with HIV in the rural South. J Health Psychol. 2020. Available from: https://doi.org/ $10.1177 / 1359105320926526$.

55. Brown JL, Vanable PA, Carey MP, Elin L. Computerized stress management training for HIV+ women: a pilot intervention study. AIDS Care. 2011;23:1525-32.
56. Mgbako O, Miller EH, Santoro AF, Remien RH, Shalev N, Olender $\mathrm{S}$, et al. COVID-19, telemedicine, and patient empowerment in HIV care and research. AIDS Behav. Springer. 2020;24:1990-3.

57. Rogers BG, Coats CS, Adams E, Murphy M, Stewart C, Arnold T, et al. Development of telemedicine infrastructure at an LGBTQ+ clinic to support HIV prevention and care in response to COVID19, Providence, RI. AIDS Behav. Springer. 2020;24:2743-7.

58. Young SD, Schneider J. Clinical care, research, and telehealth services in the era of social distancing to mitigate COVID-19. AIDS Behav. Springer. 2020;24:2000-2.

59. Remien RH, Stirratt MJ, Nguyen N, Robbins RN, Pala AN, Mellins CA. Mental health and HIV/AIDS: the need for an integrated response. AIDS. 2019;33:1411-20.

Publisher's Note Springer Nature remains neutral with regard to jurisdictional claims in published maps and institutional affiliations. 